\title{
EUCALYPTRA PUNCTULATA SCHAUS (LEPIDOPTERA: NOCTUIDAE) EM PASTAGEM NO MUNICÍPIO DE MONTE ALEGRE DO SUL, ESTADO DE SÃO PAULO (1)
}

\author{
ANDRÉ LUIZ LOURENÇÃO (2,4), CARLOS JORGE ROSSETTO (2) \\ e IGNÁCIO JOSÉ DE GODOY $\left({ }^{3}\right)$
}

\begin{abstract}
RESUMO
Em setembro de 1982, em pastagem situada no município de Monte Alegre dó Sul, SP, foi observada infestação de lagartas de Eucalyptra punctulata Schaus (Lepidoptera:Noctuidae). Na área inspecionada, formada de grama-batatais (Paspalum notatum (L.) Flügge), ocorriam outras invasoras - Melinis minutiflora Beauv., Andropogon leucostachyus H.B.K. e A. bicornis L. - também com sinais de alimentação das lagartas. Estas permaneciam durante o dia no fundo de buracos semelhantes a pequenas trincheiras, de 7-10cm de comprimento por 1,5-2 de largura, com profundidade de aproximadamente $20 \mathrm{~cm}$, caracterizando comportamento noturno. Em cada buraco, foi encontrada apenas uma lagarta. A pupa $\epsilon$ protegida por um casulo confeccionado com pecíolos e outras partes vegetais secas.
\end{abstract}

Termos de indexação: Eucalyptra punctulata Schaus, pastagem, Paspalum notatum (L.) Flügge, Melinis minutiflora Beauv., Andropogon leucostachyus H.B.K., Andropogon bicornis $\mathrm{L}$.

(1) Trabalho apresentado no XII Congresso Brasileiro de Zoologia, realizado em Campinas (SP), de 27 de janeiro a $1^{\circ}$ de fevereiro de 1985 . Recebido para publicação em 11 de outubro de 1984. (SP).

(2) Seção de Entomologia Fitotécnica, Instituto Agronómico (IAC), Caixa Postal 28, 13001 Campinas

(3) Seçāo de Oleaginosas, IAC. 
Em uma propriedade do município de Monte Alegre do Sul, SP, situada no bairro dos Limas, cuja atividade predominante é a criação de gado leiteiro, foi constatada, em setembro de 1982, em uma encosta destinada a pastagem, a presença de numerosas áreas pequenas com vegetação comida de forma irregular, deixando o solo nu. No centro de cada uma dessas áreas havia um buraco, em forma de pequena trincheira, de aproximadamente $7-10 \mathrm{~cm}$ de comprimento por $1,5-2 \mathrm{~cm}$ de largura. Abertos diversos buracos, verificou-se ser sua profundidade de cerca de $20 \mathrm{~cm}$, no fundo dos quais se abrigava apenas uma lagarta (Figura 1). Esse tipo de abrigo sugeriu ser eficiente na manutenção de temperatura adequada ao inseto, já que, na tentativa de controlar a infestação, o agricultor havia ateado fogo na pastagem atacada, queimando toda a vegetação, sem, contudo, afetar as lagartas, que, no dia seguinte, apresentavam-se aparentemente sadias no fundo do abrigo.

$\mathrm{Na}$ área de grama-batatais (Paspalum notatum (L.) Flügge) infestada, ocorriam diversas invasoras que também mostravam sinais de ataque pelas lagartas: capim-membeca (Andropogon leucostachyus H.B.K.), capim rabo-de-burro (A. bicornis L) e capim-gordura (Melinis minutiflora Beauv.) (5).

Durante a inspeção, realizada no período diurno, encontraram-se lagartas apenas no fundo dos abrigos, a maioria delas em final de ciclo, com cerca de $3,5-4,5 \mathrm{~cm}$ de comprimento. Em alguns buracos, encontrou-se a pupa protegida por um casulo de forma oblonga, confeccionado com peciolos e outras partes vegetais secas (Figura 1). Vinte lagartas foram levadas para Campinas e mantidas em laboratório. Para obtenção dos adultos, utilizaram-se frascos de vidro de $12 \mathrm{~cm}$ de diâmetro por $8 \mathrm{~cm}$ de altura, com terra até em cima e com mudas de capimgordura; sobre essa superfície, colocou-se uma ou duas lagartas. Gaiolas teladas cilíndricas, com altura de $20 \mathrm{~cm}$, protegeram individualmente esses frascos. Durante o dia, as lagartas permaneceram imóveis na superficie do solo; todavia, na manhã seguinte, todas haviam iniciado a abertura do próprio abrigo, tendo algumas já alcançado o fundo do vidro (Figura 2). A seguir, a cada dois dias, foram trocadas as mudas do capim-gordura de cada frasco, a fim de se ter sempre foIhas túrgidas disponiveis para alimentação. As lagartas confirmaram seu comportamento tipicamente noturno observado em campo, sendo que nunca foram vistas na superfície da terra durante o dia em todo o tempo em que ficaram em lajoratório.

Os adultos emergidos foram montados, catalogados sob o número 6735 na coleção da Seção de Entomologia Fitotécnica do Instituto Agronômico, e identificados como Eucalyptra punctulata Schaus (Lepidoptera: Noctuidae) (Figura 3) (6).

${ }^{5}$ ) Os autores agradecem ao Dr. Condorcet Aranha, Seção de Botânica Econômica, Instituto Agronômico, a identificação das espécies vegetais.

(6) Os autores agradecem ao Dr. Vitor O. Becker, Centro de Pesquisa Agropecuária dos Cerrados, EMBRAPA, a identificação do inseto. 
$\mathrm{Na}$ literatura, não foi encontrada nenhuma citação dessa espécie ou mesmo do gênero, o que leva os autores a supor que possivelmente não exista outros trabalhos além da descrição original, o que motivou a elaboração da presente comunicação.

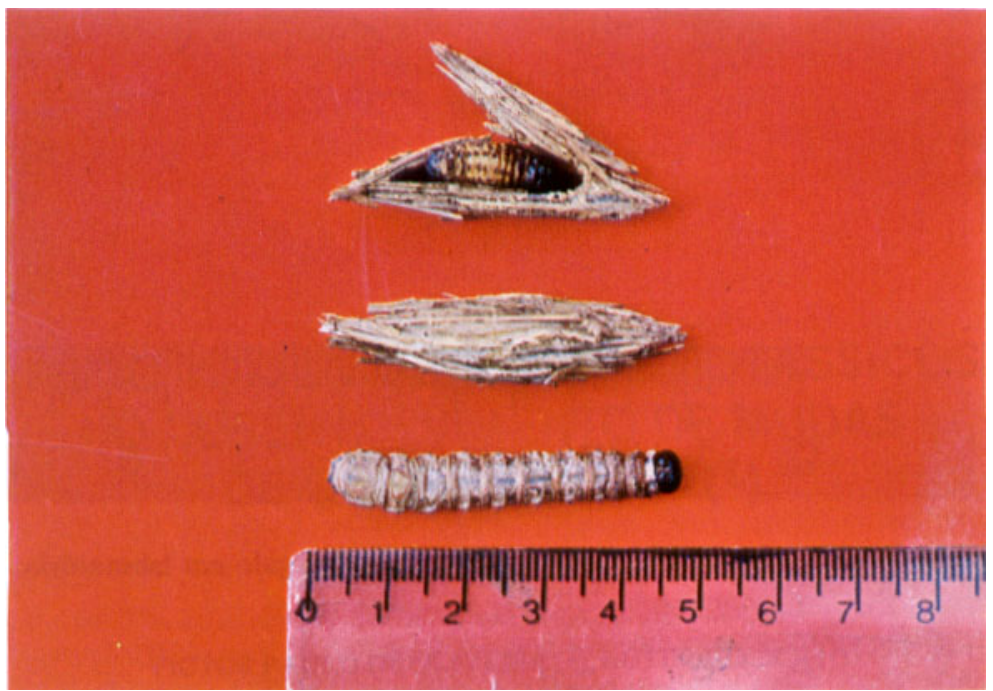

FIGURA 1. Lagarta, pupa e seu casulo protetor, de Eucalyptra punctulata Schaus. Campinas, 1982.

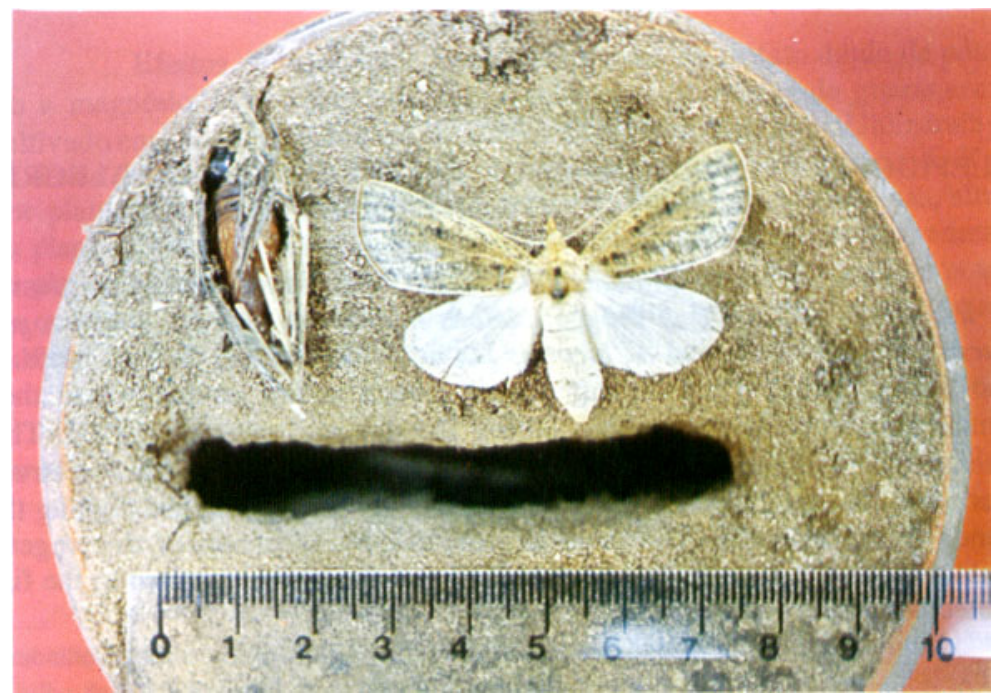

FIGURA 2. Pupa, aduito e buraco feito pela larva de Eucalyptra punctulata Schaus em condições de laboratório. Campinas, 1982. 


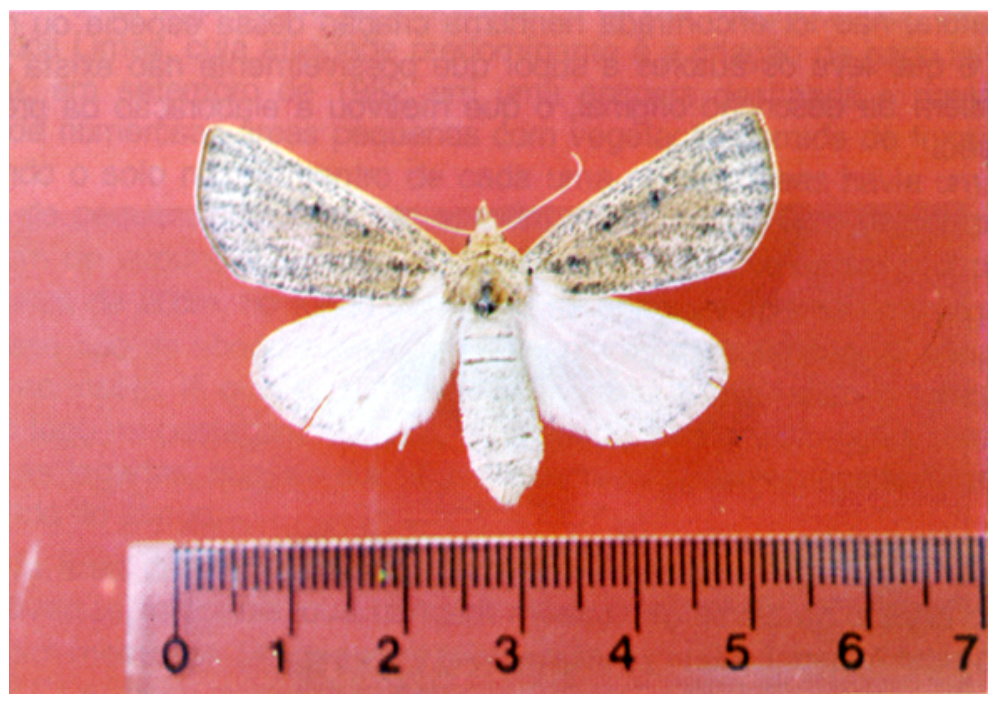

FIGURA 3. Adulto de Eucalyptra punctulata Schaus, emergido em laboratório. Campinas, 1982.

\section{SUMMARY}

\section{EUCALYPTRA PUNCTULATA SCHAUS \\ (LEPIDOPTERA: NOCTUIDAE) ON PASTURE IN MONTE ALEGRE DO SUL COUNTY, STATE OF SÄO PAULO, BRAZIL}

The larvae of $E$. punctulata Schaus were found feeding on grasses of Paspalum notatum (L.) Flügge, Melinis minutiflora Beauv., Andropogon leucostachyus H.B.K. and A. bicornis L., in Monte Alegre do Sul, State of São Paulo, Brazil. They dig up a small trench in the ground where they remain protected at the bottom during the day and pupate later on. This trench is $7-10 \mathrm{~cm}$ long, $1.5-2 \mathrm{~cm}$ wide and about $20 \mathrm{~cm}$ deep. Only one larvae was found in each trench. Only nocturnal activity for feeding and digging the trench were observed. The pupa is protected by a cocoon of dry vegetal parts. Part of the pasture had been burned and the larvae survived to the fire protected inside the trenchs.

Index terms: Eucalyptra punctulata Schaus, grass, Paspalum notatuom (L.) Flügge, Melinis minutiflora Beauv., Andropogon leucostachyus H.B.K., Andropogon bicornis L. 